\title{
Indicators of exhaustion and stress markers in endurance horses
}

\author{
STEFAN DJOKOVIĆ ${ }^{1}$, LAZAR MARKOVIĆ ${ }^{1}$, VLADAN DJERMANOVIĆ ${ }^{2}$, RUŽICA TRAILOVIĆ ${ }^{1}$
}

${ }^{1}$ Faculty of Veterinary Medicine, ${ }^{2}$ Agricultural Faculty, University of Belgrade, Bul. Oslobođenja 18, 11000 Beograd, Serbia

Received 05.12.2020

Acepted 30.01.2021

Djoković S., Marković L., Djermanović V., Trailović R.

Indicators of exhaustion and stress markers in endurance horses

Summary

Prolonged training and physical effort in endurance horses can influence the performance of the endurance horses negatively. The negative impact of the event is especially noticeable if venues are demanding, i.e. bad weather conditions or demanding grounds, high altitude and especially in cases of insufficiently fit horses. One of the most important factors that influence equine performance is abundance of oxygen in the blood, which is directly related to the air oxygen content and changes with atmospheric pressure, so that high altitude and low air pressure demand additional work from horses and accelerate fatigue. The authors goal was to investigate the influence of workload in endurance racing on sport horse organism. A total of 18 trained and competing endurance horses enrolled in a $60 \mathrm{~km}$ long endurance race organized on Zlatibor Mountain were included in our survey. Due to the difficult track 8 horses were disqualified due to lameness, and high heart rate and respiration. Only 10 horses completed the race and these animals were submitted to basic physical, clinical and laboratory examinations, in order to evaluate fatigue and stress reaction in endurance horses in Serbia. Results of the clinical and laboratory testing obtained show significant changes in all parameters evaluated which we attributed to physical effort in all 10 horses that finished the race in comparison with the values obtained before the race. In conclusion, 10 horses finished the race and were tested, and they indicated significant alterations in physiological parameters showing stress reaction. The evaluated parameters decreased into physiological interval values during the 5 days following the race.

Keywords: cortisol, endurance, exhaustion, horse, stress

Intensive physical activity leads to a variety of changes and adaptations, which may influence health and racing performance of horses. Key changes in the body occur due to the loss of fluids and electrolytes, primarily through sweating and ventilation, leading to accumulation of harmful metabolic products and consequential cell damage. These changes lead to the onset of symptoms of fatigue, exhaustion and stress, with prolonged delayed reaction that can be monitored in post exercising period $(10,30)$.

Intensity of fatigue, exhaustion and stress depend on the amount of workload, environmental conditions under which the work is done and level of fitness and soundness of the horse. Beside the physical fatigue and accumulation of harmful metabolites, external conditions - i.e. temperature, humidity, wind, altitude and track quality (hard, heavy, slippery, deep, steep) - have a significant role in building fatigue due to the large distances that endurance horses have to cover. Sweating, especially during hot, humid days can lead to dehydration and electrolyte disbalance and due to the development of metabolic syndrome and disqualification, and in some cases, a horse can even collapse before reaching the finish $(3,4,17)$. Subclinical injuries of locomotory apparatus can lead to lameness in late phases of the competition, while incorrect shoeing, respiratory and cardiovascular problems, also influence the outcome of the race and horses with any of these conditions usually find it harder to tolerate ambiental conditions $(3,4,19)$.

Physical activity can lead to visible fatigue, depression, difficult breathing, excessive sweating and/or lameness. Physical activity also induces changes of several hematological and biochemical parameters. Inadequate muscle perfusion can lead to anaerobic glucose metabolism and the building up of acid metabolites, predominantly lactic acid, lowering $\mathrm{pH}$ and the depletion of buffering capacities of body fluids $(5,21,23)$. Horses loose large amounts of fluids through sweating, which causes an increase in total protein and albumin concentration, development of hemoconcentration and an increase in packed cell 
volume (PCV). In addition, PCV is also enlarged by expulsion of reserve amounts of blood from the spleen $(8,20)$. A special problem, leading to the disbalance of sodium, potassium, calcium ion concentrations, which also negatively influences muscle work, is electrolyte loss trough sweating in horses (7). At the same time, muscle strain leads to release of muscle enzymes to the blood stream, whose increased presence in the blood indicates muscle cell damage, the state of exhaustion and readiness of the horse for race and competition. Taken altogether it reflects stress of the organism, that is manifested by increased release of the stress hormone cortisol. Consequently these parameters can be indicators of horse fitness for racing and competition, the level of exhaustion and, finally, the stress reaction of the horse $(15,21,24,29)$.

Hypercortisolemia lead to numerous metabolic disturbances and also provokes leukocytosis, neutrophilia, lymphopenia and eosinopenia $(9,12,14)$.

The influence of a high intensity work load in racehorses, mainly Thoroughbreds and Standardbreds have been evaluated in detail. However, studies referring to a prolonged, low intensity work load typical for endurance rides in Serbia are few (2) compared to the literature data $(14,23)$. The goal of the study was to evaluate changes that an endurance race provokes in the organism of horses, in order to enable the safer estimation of fitness, and the competence of the horse for the expected work load, easier recognition of fatigue and stress during a race and to obtain information concerning alterations caused by fatigue and stress, enabling efficient prevention of larger damage and injuries caused by excessive effort as well as easier treatment of complications caused by a surplus workload.

\section{Material and methods}

A total of 18 horses: 9 thoroughbreds and 9 warmbloods, i.e. 8 geldings, 6 stallions, and 4 mares, aged 5-10 years ( 8 on average), enrolled in a $60 \mathrm{~km}$ long endurance race were evaluated. All horses competing were daily trained at an altitude of $120 \mathrm{~m}$, in good physical condition, clinically sound, without signs of injuries. Horses were fed hay and oats and/or barley, with supplementation of mineralized salt.

The competition took place on the Zlatibor Mountain on an average altitude of $1000 \mathrm{~m}$. The track was of medium difficulty, with some slopes, the ground was hard - dirt with some rocks, grass at times. Environmental conditions were good, the temperature at the start was $12^{\circ} \mathrm{C}$, the daily high was around $20^{\circ} \mathrm{C}$, and humidity was $60 \%$. One day before the race the horses were transported for four hours from stables in Belgrade to the venue in the morning and stabled on a local farm. The race started at $8 \mathrm{AM}$. Veterinary control, that consisted of inspection, auscultation of heart and lung and temperature, heart rate and respiration rate check was performed before the start, on a vet check after $40 \mathrm{~km}$, and finally at the end of the race. The ground jury and riders accepted and approved of our testing of the horses.

Blood samples were taken from all 18 horses 4-5 hours after transport -24 hours before the start. After the night rest and first morning vet check, the race started at 8.00 AM. The horses that finished the race were clinically examined at the check points and did not show any signs of dehydration or metabolic disturbance. The second blood sampling was performed one hour after the race. Ten horses that had finished the race were followed for four more consecutive days after the horses had returned to their home stables in Belgrade (postrace day 2, 3, 4 and 5). Blood samples were collected each day in the morning before training session. The horses excluded at vet check points were excluded from further evaluation.

Blood was obtained by jugular vein puncture and collected in EDTA vacutainers for hematological examination, and in SST gel and activator of coagulation vacutainers were for serum biochemical analyzes. Blood samples for immediate hematological and biochemical testing were taken to the laboratory 2 to 4 hours after the sampling. The count of red blood cell (RBC), white blood cell (WBC), differential leucocytes, platelet count $(\mathrm{Pt})$, hemoglobin concentration $(\mathrm{Hb})$, packed cell volume (PCV) and red blood cells indices: mean cell volume (MCV), mean cell hemoglobin $(\mathrm{MCH})$, mean cell hemoglobin concentration (MCHC) were established. The activity of enzymes AST and CK, total protein concentration, albumin concentration, total bilirubin, cortisol concentration and concentration of $\mathrm{Ca}^{2+}, \mathrm{Na}^{+}, \mathrm{Cl}^{-}$and $\mathrm{K}^{+}$ions were determined in serum samples.

All hematological analysis was done on the hematological analyzer "Diatron". Total protein, albumin and bilirubin concentration were estimated on Astra Bekmen USA analyzer. Cortizole concentration was measured with CMIA - chemiluminescent immunoassay with microparticles on Architect 2000SR (Abbott) analyzer.

The data obtained were statisticaly analyzed by MsExell and the importance of differences for each parameter evaluated was determined by Turkey's test.

\section{Results and discussion}

Clinical and laboratory findings in all horses were normal before the race, and the variations established were small (Tab. 1).

During the race (workload), 8 horses were disqualified ( 2 for getting lost, 3 due to lameness and 3 for too a high heart rate) and 10 finished the race. In comparison to the values measured on first examination $(24 \mathrm{~h}$ before the race), $\mathrm{RBC}$, hemoglobin concentration, and PCV were significantly increased after the race and during the next five days these values gradually returned to prerace levels (Tab. 1). Lowest values were recorded on the fifth day postrace. Increased WBC values, mostly sequential to increased neutrophilia, reflected in Ne/Ly ratio were observed after the race in all individual horses (Tab. 1). After the rest total leukocyte count returned to the prerace levels during the following 5 days.

Total protein and albumin concentration did not change significantly during the race, but the entry values were relatively high in samples collected 24 hours before the race (Tab. 2). Unlike total protein concentration, bilirubin concentration rose significantly 
Tab. 1. Values of basic hematological parameters in endurance horses before and after the workload $(\overline{\mathbf{x}} \pm \mathrm{SD})$

\begin{tabular}{|c|c|c|c|c|c|c|}
\hline Parameter & Before the race & After the race & 2. days after the race & 3. days after the race & 4. days after the race & 5. days after the race \\
\hline $\operatorname{RBC}\left(\times 10^{12} / I\right)$ & $9.97 \pm 1.33$ & $10.94 \pm 1.43$ & $9.76 \pm 1.41$ & $9.81 \pm 1.05$ & $9.55 \pm 0.77$ & $8.94 \pm 0.64^{*}$ \\
\hline PCV (\%) & $42.99 \pm 7.18$ & $47.13 \pm 8.80$ & $41.04 \pm 7.38$ & $39.96 \pm 5.21$ & $39.73 \pm 3.30$ & $37.23 \pm 3.16^{*}$ \\
\hline $\mathrm{Hb}(g / l)$ & $140.53 \pm 23.63$ & $160.67 \pm 21.04$ & $137.78 \pm 24.22$ & $135.11 \pm 19.37$ & $133.33 \pm 16.75$ & $128.11 \pm 17.50$ \\
\hline $\operatorname{MCV}(\mathrm{fl})$ & $43.00 \pm 2.40$ & $43.89 \pm 2.52$ & $42.00 \pm 2.74$ & $40.33 \pm 2.18^{*}$ & $42.11 \pm 0.67$ & $42.23 \pm 1.83$ \\
\hline MCH (pg) & $14.07 \pm 0.97$ & $14.38 \pm 0.81$ & $14.03 \pm 0.90$ & $13.70 \pm 0.87$ & $14.03 \pm 0.67$ & $13.88 \pm 0.75$ \\
\hline MCHC (g/l) & $325.1 \pm 6.83$ & $325.88 \pm 4.45$ & $337.33 \pm 13.33^{*}$ & $338.44 \pm 10.20^{* *}$ & $326.50 \pm 7.56$ & $328.80 \pm 4.82$ \\
\hline WBC $\left(\times 10^{9} /\right)$ & $8.10 \pm 1.19$ & $14.01 \pm 2.36^{* * *}$ & $10.22 \pm 1.24^{* *}$ & $9.15 \pm 1.42$ & $8.16 \pm 1.49$ & $8.47 \pm 0.79$ \\
\hline $\operatorname{Ly}\left(\times 10^{9} / l\right)$ & $3.49 \pm 0.70$ & $2.15 \pm 0.87^{* *}$ & $3.93 \pm 2.43$ & $3.71 \pm 1.66$ & $3.84 \pm 1.44$ & $3.60 \pm 0.62^{*}$ \\
\hline Mo $\left(\times 10^{9} / I\right)$ & $0.24 \pm 0.14$ & $0.44 \pm 0.21^{*}$ & $0.33 \pm 0.25$ & $0.25 \pm 0.15$ & $0.32 \pm 0.23$ & $0.19 \pm 0.06$ \\
\hline $\mathrm{Ne}\left(\times 10^{9} / \mathrm{l}\right)$ & $4.38 \pm 1.24$ & $11.44 \pm 2.45^{* * *}$ & $5.99 \pm 2.69$ & $5.34 \pm 1.89$ & $4.21 \pm 1.57$ & $4.84 \pm 0.84$ \\
\hline $\mathrm{Ne} /$ Ly ratio & 1.25 & 5.32 & 1.52 & 1.44 & 1.10 & 1.34 \\
\hline
\end{tabular}

Explanations: levels of significance: *significant $\mathrm{P}<0.05$, **highly significant $\mathrm{P}<0.005$, *** very highly significant $\mathrm{P}<0.0005$; $\mathrm{SD}$ - standard deviation

Tab. 2. Values of basic blood serum biochemical parameters in endurance horses before and after the workload ( $\bar{x} \pm$ SD)

\begin{tabular}{|l|c|c|c|c|c|c|}
\hline \multicolumn{1}{|c|}{ Parameter } & Before the race & After the race & 2. days after the race & 3. days after the race & 4. days after the race & 5. days after the race \\
\hline Tot. protein $(\mathrm{g} / \mathrm{l})$ & $77.98 \pm 8.61$ & $66.18 \pm 4.46^{* *}$ & $59.89 \pm 4.08^{* * *}$ & $60.36 \pm 3.44^{* * *}$ & $59.82 \pm 5.06^{* * *}$ & $56.52 \pm 3.87^{* * *}$ \\
\hline Albumin $(\mathrm{g} / \mathrm{l})$ & $39.86 \pm 3.11$ & $38.82 \pm 2.87$ & $39.11 \pm 1.78^{*}$ & $33.89 \pm 2.34^{* * *}$ & $32.95 \pm 2.95^{* * *}$ & $32.02 \pm 4.31^{* * *}$ \\
\hline Tot. bilirubin $(\mu \mathrm{mol} / \mathrm{l})$ & $19.4 \pm 3.23$ & $34.08 \pm 9.98^{* * *}$ & $26.56 \pm 7.57^{*}$ & $23.50 \pm 4.43^{*}$ & $14.93 \pm 2.45^{* *}$ & $14.60 \pm 2.64^{* *}$ \\
\hline $\mathrm{AST}(\mathrm{IU} / \mathrm{l})$ & $126.42 \pm 45.18$ & $196.68 \pm 124.41$ & $138.32 \pm 53.47$ & $129.61 \pm 36.58$ & $186.58 \pm 83.31$ & $174.14 \pm 65.73$ \\
\hline $\mathrm{CK}(\mathrm{IU} / \mathrm{l})$ & $79.67 \pm 35.58$ & $245.67 \pm 216.20^{*}$ & $88.56 \pm 23.63$ & $69.11 \pm 18.62$ & $98.00 \pm 31.85^{*}$ & $71.20 \pm 26.33$ \\
$\mathrm{Ca}^{2+}(\mathrm{mmol} / \mathrm{l})$ & $3.15 \pm 0.22$ & $3.06 \pm 0.18$ & $3.21 \pm 0.24$ & $3.23 \pm 0.20$ & $2.91 \pm 0.31$ & $2.81 \pm 0.12^{* * *}$ \\
\hline $\mathrm{K}^{+}(\mathrm{mmol} / \mathrm{l})$ & $3.98 \pm 0.56$ & $3.39 \pm 0.67^{*}$ & $4.58 \pm 1.42$ & $4.08 \pm 0.45$ & $4.14 \pm 1.16$ & $4.33 \pm 0.54$ \\
\hline $\mathrm{Na}^{+}(\mathrm{mmol} / \mathrm{l})$ & $136.59 \pm 1.63$ & $140.07 \pm 5.31$ & $136.03 \pm 4.02$ & $131.61 \pm 11.20$ & $123.45 \pm 13.11^{* *}$ & $128.00 \pm 16.45$ \\
\hline $\mathrm{Cl}^{-}(\mathrm{mmol} / \mathrm{l})$ & $101.22 \pm 1.22$ & $99.81 \pm 6.03$ & $98.86 \pm 3.43$ & $98.73 \pm 15.39$ & $87.68 \pm 11.39^{*}$ & $92.10 \pm 14.74$ \\
\hline $\mathrm{Cortizol}(\mathrm{nmol} / \mathrm{l})$ & $47.77 \pm 14.60$ & $97.13 \pm 31.14^{* * *}$ & $52.51 \pm 21.61$ & $50.78 \pm 11.70$ & $35.26 \pm 8.83^{*}$ & $34.18 \pm 7.75^{*}$ \\
\hline
\end{tabular}

Explanations: as in Tab. 1

after the race, and returned gradually to physiological values during next five days (Tab. 2). Muscle enzymes activities were elevated after the race, and returned to the prerace levels gradually during the first two days of rest, and after the first postrace training (after 3 days of rest) these values increased again. Statistically significant differences in values of tested ion concentrations were not detected. Bilirubin concentration was significantly increased after the race and concentration decreased in postrace days. Albumin concentration increased starting from the second postrace day and the increase was significant on days 3,4 , and 5 after the race when the training continued. Serum AST activity stayed within physiological interval values during the whole evaluation period. Serum CK activity was significantly increased postrace and returned to the normal values on the second day of evaluation and increased again when training restarted. Cortisol concentration was significantly increased after the race and the increase coincides with highest $\mathrm{Na} / \mathrm{Ly}$ ratio.

The results obtained in our study were similar to those reported in the literature. Fluid and electrolyte loss together with expulsion of reserve amounts of blood cells from the spleen lead to the increase in blood viscosity and changes in blood pressure, which was also reported $(13,23)$. An important effect of low intensity long term effort is fluid and electrolyte loss, primarily through sweating and breathing, which can range between 10 to 151 per hour. Losses of some 20 to 401 of fluids (4-7\% of body weight) during a $80 \mathrm{~km}$ endurance race were recorded by other authors (13). It is very important to mention that horses produce hypertonic sweat with $159 \mathrm{mmol} / 1$ of $\mathrm{Na}^{+}, 32 \mathrm{mmol} / 1$ of $\mathrm{K}^{-}$and $165 \mathrm{mmol}^{-} \mathrm{Cl}^{-}$that can lead to significant electrolyte loss. Several studies found lowering of blood levels of electrolytes in endurance horses (6, $25,28)$. Additionally, low oxygen concentration in air due to lower air pressure, difficult track and conditions are leading to increased stress of horses and increased production of cortisol $(9,11,14,18)$.

Horses tested in this study participated previously in training and endurance races where they exhibited solid form. Examination of the horses during the rest before the race showed normal values of tested hematological and biochemical parameters and only minor variations, consistant with gender, breed and temperament 
were observed. These findings are primarly reffered to RBC parameters. Initial values of hematological parameters were slightly increased; i.e. RBC count was $9.97 \pm 1.33 \times 10^{12} / 1$ and PCV was $42.99 \pm 7.181 / 1$, and the findings were expected as reaction to prolonged strong training, transportation before the race, high altitude, and numerous thoroughbreds and their crosses included in our study. Thoroughbreds involved in this study had higher PCV, RBC, and hemoglobin concentration values compared to data from the literature which mostly evaluated warmbloods and Arabs horses. After the race, these values were additionally increased, RBC was $10.94 \pm 1.3 \times 10^{12} / 1$, representing increase of $10.7 \%$, i.e. hemoglobin concentration was $160.67 \pm 21.04 \mathrm{~g} / \mathrm{l}$ (increase of $14.3 \%$ ), and PCV was $47.13 \pm 8.801 / 1$ (increase of $9.6 \%$ ). The increases of hematological parameters established in our evaluation were significant. These findings probably occured due to hipoxia caused by high altitude and increased work during the race resulting in expulsion of reserve amounts of blood from the spleen induced by work load, hypoxia, low oxygen and adrenergic induction of contraction involving smooth muscle of the capsule and trabeculae of spleen also described in literature $(15,22,24,27)$. These changes were reported in the thoroughbreds (24), which are capable of increasing PCV for over 50\% compared to the rest values in a very short time. In our study, the PCV increase established postrace was moderate $9.6 \%$ in comparison with the prerace data, which may be challenging for interpretation because of the delayed blood sampling after the race. Additionally fluid loss through sweating and respiration plays an important role in increase of PCV. The role of sweating and respiration and fluid loss occurs during the race, in correlation to the degree of the fatigue of the horse, reflected in high PCV level after the workload, so that RBC count established postrace would reflect the real status of the animal less accurately $(7,16)$. As it is impossible to neglect effects of sweating, although horses were given water during the vet check and before the sampling, some increase of the established PCV values could be atributed to sweating, although blood sampling was performed one hour after the finish.

Two days after the race, the decline in values of all tested hematological parameters, with small variations was observed. The continuing decline was established until the fifth day of rest. After 5 days of rest the final values of $\mathrm{RBC}$ were $11 \%$ lower than the entry values ( $24 \mathrm{~h}$ before race) and 19\% lower than values obtained after the race. The same decreasing trend of values was shown in hemoglobin concentration and PCV value. As the observed RBC decrease coincides with the increasing of bilirubin concentration, it can be concluded that work load led to some destruction of red blood cells. Stewart et al. (15) have found increased destruction of $\mathrm{RBC}$ in race horses after great efforts, as well as because of delayed stress reaction induced by heavy work and training. During the recovery, 16 to 24 hours after the race transient hyper bilirubinemia can be found that, according to these authors, confirms erythrocyte destruction.

The observed influence of workload on the WBC number was particularly interesting in our study. The initial values were within normal limits, while after the work load, significant increase was observed in total leukocyte and neutrophil count, with some decline in lymphocyte numbers, although it was expected that the number of lymphocyte cells should increase during the work load, and eventually decrease later as a result of the action of stress mechanisms. High intensity work load such as flat races - gallop or trotting - lead to increased lymphocyte values, during the race and decrease of its numbers afterwards, as the result of delayed effects of stress mechanisms. In this case the most important finding is an increased granulocyte count, which can be attributed primarily to the increase in neutrophil count. According to this, an increased $\mathrm{Ne} /$ Ly count shows the highest values in blood samples after the work load-race, which coincides with highest cortisol values.

All obtained results are consistent with date in the literature. Authors who have studied the influence of short-term maximum load on the number of leukocytes and leukocyte formula in racing horses presented that the number of leukocytes did not change under the influence of short-term loads. They also found that immediately after high intensity training (gallop) and after the race there is a decrease in Ne/Ly ratio due to a relative increase in the number of circulating lymphocytes $(1,24)$. Unlike short-term loads, a prolonged work load leads to significant leukocytosis that may last up to 48 hours. This occurs as a result of neutrophilia due to the increased release of cortisol $(1,14)$. Hypercortisolemia at the same time can lead to eosinopenia, which definitely does not affect the value of the $\mathrm{Ne} / \mathrm{Ly}$ ratio due to the predominant increase in the number of neutrophils.

Our results showed that total protein concentration decreased by some $16 \%$ compared to the values before the race, and on the fifth day after the race these values were $28 \%$ under the initial value. The fact that horses were watered before sampling certainly raises the question whether the estimated total protein concentration was a realistic reflection of the status of horses after prolonged efforts. According to literature, it is expected to observe a slight increase in total protein concentration due to the fluid loss and dehydration after heavy exercise $(24,26)$. Unfortunately, the finding of relatively high values of total protein in blood samples sampled before races are rising concerns in persistent dehydration that does not allow adequate evaluation of fluid loss during the race, especially with watering during the vet check that cushioned dehydration. Sodium 
concentration showed a slight increase after the race and it returned to its previous levels a day after the race. Potassium concentrations decreased $13 \%$ after the race and returned to previous levels one day after the race. Both a moderate decrease of potassium concentration in blood serum has been recorded after endurance races and even slight increases $(8,16,20)$. Many authors sugest that lowering of cell membrane potential is induced with low a concentration of intracellular potassium and an increase of extracellular calcium concentration, which in high intensity races is an important factor that leads to the building of fatigue (7).

Serum levels of chlorine remained within the standard values, with a drop for $2 \%$ after the race and then changing to $8 \%$ below standard values five days after the race, but the changes observed were not statistically significant. Chlorine losses during prolonged work loads can be significant. Most of the researchers recorded decreasing values of serum chloride concentration in endurance races $(8,16)$. On the other hand, the effects of a high intensity work load never showed important variations of blood chlorine concentration in blood (23), despite the increase of sodium concentration and total protein in plasma, primarily caused by the shifting of extracellular fluids. The reason for this could be a high increase of lactate concentration, that is responsible for chlorine exchange (8).

Cortisol concentration in blood of examined horses was within normal limits before the race. After the race, an increased serum cortisol level (206\% increase) was observed in all horses in our evaluation, and the established increase was highly significant $(\mathrm{p}<0.005)$. It could be a consequence of long lasting workload stress. It was found that the increase in cortisol levels at the same workload were significantly smaller than in better trained Standardbreds (12). On the other hand, it was described that endurance horses have a higher increase in cortisol levels than show jumping horses (9). It has been suggested (23) that significant leukocytosis, which can take up to 48 hours after longterm effort, is a direct result of neutrophilia caused by cortisol release. A significant increase in leukocyte number due to neutrophylia was also observed in our evaluation.

Our evaluation showed that a prolonged physical workload of endurance horses leads to complex changes in the metabolism of horses. The prolonged workload lead to changes in basic hematological and biochemical parameters, including stress parameters which was established in our evaluation. Thanks to the homeostatic mechanisms of the body, clinically visible symptoms of overload, fatigue and stress can be compensated (hidden), until final moments when horses suddenly collapse, injure themselves or even die $(3,4,17,30)$. In our evaluation, only eliminations due to fatigue, lameness and exhaustion occurred during the race. Overall, the observed changes in our study showed considerable individual differences among horses. The large dissemination evident in all parameters evaluated could also be the result of breed related differences, which were described in the literature, especially when thoroughbreds and Arabs are compared.

The studied group of horses showed significant differences in values of hematological and biochemical parameters and cortisol compared to the pre-race values, thus showing a strong stress reaction.

The hematological and biochemical changes observed in our evaluations were more significant compared to those described in literature which mostly refers to effects of endurance races in Arabs and Angloarabs suggesting that the Arabs are more suitable for competition in long distance riding compared to thoroughbred horses.

The results obtained show that further investigation on the impact of endurance races on horses in Serbia should be performed with the focus on effects of workload on different breeds involved in this sport in our country.

\section{References}

1. Cywiska A., Wyszynska Z., Gorecka R., Szarska E., Witkowski L., Dziekan P., Winnicka A., Schollenberger A.: The effect of the $162 \mathrm{~km}$ endurance ride on equine peripheral blood neutrophil and lymphocyte functions. Pol. J. Vet. Sci. 2010, 13, 279-285.

2. Djokovic $S$.: Comparative study of the concentration of atrial natriuretic atrial peptide in Domestic mountain horse, Arabian and English Thoroughbred after different types of work load. Master's thesis, Faculty of Veterinary Medicine University of Belgrade. Belgrade 2016.

3. Dumont C. B. S., Okiyama F. T. M., Barreto-Vianna A. R. C., Lima E. M. M. The distance run is not the determining factor on the occurrence of electrolytic change for equine athletes disqualified in endurance competitions. Pak. Vet. J. 2014, 34, 239-242

4. Fielding C. L., Meier C. A., Balch O. K., Kass P. H.: Risk factors for the elimination of endurance horses from competition. J Am. Vet. Med. Assoc. 2011, 239, 493-498.

5.Hura V., Novotny F., Boldižar M., Redl M., Noskovičova J., Hornak S., Petrovič V., Lazar G., Kovač G.: Biochemical responses to a non-standard exercise in horses trained for jumping. Acta Vet. Brno 2013, 82, 161-167.

6. Jenkinson D. M., Elder H. Y., Bovell D. L.: Equine sweating and anhidrosis part 1 - Equine sweating. Veterinary Dermatology 2006, 17, 361-392.

7. Jose-Cunilleras E.: Abnormalities of body fluids and electrolytes in athletic horses, [in:] Hinchliff K. W., Kaneps A. J., Geor R. J.: Equine Sports Medicine and Surgery, Saunders Elsevier, Edinburgh 2014, 881-900.

8. Jose-Cunilleras E., McKeever K. H.: Body fluids and electrolytes: responses to exercise and training, [in:] Hinchliff K. W., Kaneps A. J., Geor R. J.: Equine Sports Medicine and Surgery, Saunders Elsevier, Edinburgh 2014, 837-854.

9. Kolk J. H. Van der: Endocrine function during exercise and response to training, [in:] Hinchliff K. W., Kaneps A. J., Geor R. J.: Equine Sports Medicine and Surgery, Saunders Elsevier, Edinburgh 2014, 768-785.

10. Larsson J., Pilborg P. H., Johansen M.: Physiological Parameters of Endurance Horses Pre- Compared to Post-Race, Correlated with Performance: A Two Race Study from Scandinavia. ISRN. Veterinary Science 2013, Article ID 684353, 12 pages, doi: 10.1155/2013/684353.

11. Makara G. B., Haller J.: Non-genomic effects of glucocorticoids in the neural system: evidence, mechanisms and implications. Prog. Neurobiol. 2001, 65, 367-390.

12. Marc M., Parvizi N., Ellendorff F., Kallweit E., Elsaesser F.: Plasma cortisol and ACTH concentrations in the warmblood horse in response to a standardized treadmill exercise test as physiological markers for evaluation of training status. J. Anim. Sci. 2000, 78, 1936-1946

13. McConaghy F. F., Hodgson D. R., Evans D. L., Rose R. J.: Equine sweat composition: effects of adrenaline infusion, exercise and training. Equine Vet. J. 1995, 20, 158-164. 
14. McGowan C. M., Geor R. J.: Endocrine and metabolic disorders of the equine athlete, [in:] Hinchliff K. W., Kaneps A. J., Geor R. J.: Equine Sports Medicine and Surgery. Saunders Elsevier, Edinburgh 2014, 787-796.

15. McKenzie E. C.: Hematology and serum biochemistry of the equine athlete, [in:] Hinchliff K. W., Kaneps A. J., Geor R. J.: Equine Sports Medicine and Surgery, Saunders Elsevier, Edinburgh 2014, 921-929.

16. Munoz A., Riber C., Trigo P., Castejon-Riber C., Castejon F. M.: Dehydration, electrolyte imbalances and renin-angiotensin-aldosterone-vasopressin axis in successful and unsuccessful endurance horses. Equine Vet. J. 2010, 42, 83-90.

17. Nagy A., Murray J. K., Dyson S.: Elimination from elite endurance rides in nine countries: a preliminary study. Equine Vet. J. 2010, 42, 637-642.

18. Peckett A. J., Wright D. C., Riddel M. C.: The effects of glucocorticoids on adipose tissue lipid metabolism. Metabolism 2011, 60, 1500-1510.

19. Robert C.: Veterinary aspects of training and racing endurance horses, [in:] Hinchliff K. W., Kaneps A. J., Geor R. J.: Equine Sports Medicine and Surgery, Saunders Elsevier, Edinburgh 2014, 1083-1106.

20. Robert C., Goachet A. G., Fraipont A., Votion D. M., Van Erck E., Leclerc $J$. L.: Hydration and electrolyte balance in horses during an endurance season. Equine Vet. J. 2010, 42, 98-104.

21. Schott H. C., Marlin D. J., Geor R. J., Holbrook T. C., Deaton C. M., Vincent T., Dacre K., Schroter R. C., Jose-Cunilleras E., Cornelisse C. J.: Changes in selected physiological measurements in elite horses competing in a $160 \mathrm{~km}$ endurance ride. Equine Vet. J. 2006, 38, 37-42.

22. Smith J. E., Erickson H. H., Debowes R. M.: Changes in circulating equine erythrocytes induced by brief, high-speed exercise. Equine Vet. J. 1989, 21, 444-446.
23. Snow D. H., Kerr M. G., Nimmo M. A.: Alterations in blood, sweat, urine and muscle composition during exercise in the horse. Vet. Rec. 1982, 16, 377-384.

24. Snow D. H., Ricketts S. W., Mason D. K.: The haematological response to racing and training exercise in Thoroughbred horses, with particular reference to the leucocyte response. Equine Vet. J. 1983, 15, 149-154.

25. Spangfors $P$.: Energibalans vatske och elektrolyt forandringar under distansritt. Svensk Veterinar Tidning 1991, vol. 42, p. 55-61.

26. Stevanović J., Vitić J., Trailović R., Trailović D.: Effects of the $1600 \mathrm{~m}$ long race on proteins, lipoproteins and lipids in standardbred horses. Acta Vet. Beograd 1994, 44, 57-62.

27. Stewart G. A., Ridle C. A., Salman P. W.: Haematology of the racehorse: A recent study of Thoroughbreds in Victoria. Aust. Vet. J. 1977, 53, 353-359.

28. Stopyra A., Zarczinska K., Snarska A., Sobijech P.: Selected electrolytic, haematological and enzymatic parameters in horses during endurance races. J. Elem. 2016, 21, 1151-1159.

29. Trigo P., Castejon F., Riber C., Munoz A.: Use of biochemical parameters to predict metabolic elimination in endurance rides. Equine Vet. J. 2010, 42, 142-146.

30. Whiting J. M.: The exhausted horse, [in:] Robinson N. E., Sprayberry K. A. (eds): Current therapy in equine medicine, $6^{\text {th }}$ ed., Saunders Elsevier, St. Louis 2009, 926-929.

Corresponding author: Stefan Djoković, PhD, assistant professor, Faculty of Veterinary Medicine, University of Belgrade, Bulevar Oslobođenja 18, 11000 Beograd, Serbia; e-mail: djstefan@vet.bg.ac.rs 